African Journal of Educational Studies in Mathematics and Sciences Vol. 15, No. 2., 2019

\title{
Effect of problem-based learning on Colleges of Education students' achievement in probability and attitude towards solving probability related problems
}

\author{
H. I. ${ }^{1}$ Bukari, \& S.K. ${ }^{2}$ Asiedu-Addo
}

\begin{abstract}
This paper deals with the effect of Problem-Based Learning on Colleges of Education students' achievement in, and attitude toward Probability in Tamale Metropolitan of Ghana. The research design was quasi-experimental pre-test post-test two-group design. Convenience and simple random sampling techniques were employed to obtain a sample of 100 students which comprised of 51 students in the control group and 49 in the experimental group. Tests, questionnaire and semi-structured interview were the instruments used for data gathering. Descriptive, Independent samples t-test, ANCOVA and paired samples t-test were used in analysing data. The results indicated that there was a statistically significant difference between students of the experimental group exposed to Problem-Based Learning approach and control group exposed to Traditional Method. Problem-Based Learning developed students critical thinking, good problem solvers and self-directed learners which would lead to life-long memory of Probability concepts and its applications to real-life situations.
\end{abstract}

Keywords: $\quad$ problem-based learning; probability; achievement; attitude

\section{Background to the Study}

Attitude in terms of patience, confidence, willingness and anxiety help in problem solving in mathematics achievement. However, student's perception has created a bad public image describing mathematics as difficult, abstract, theoretical and not an interesting subject according to Arthur, Asiedu-Addo and Assuah (2017). Attitudes determine student's ability and willingness to learn a course or work on a variety of assigned tasks available. Students perceived probability as abstract in nature which often cause them to develop a negative attitude toward probability concepts (Borovnik, 2012). Probability is part of mathematics and probability as an abstract concept cannot be directly measured (Lee, Doerr, Tran \& Lovert, 2016). The conceptions students hold about probability determine how to approach probability tasks leading them into either productive or non-productive orientations. The language of probability is part of our everyday life activities, thereby creating a greater opportunity for students now and in the future in which they increasingly meet chance variation and random phenomena not only in mathematics but also in the media, meteorology, finance and social activities such as in games, sports and gambling (Pratt, 2005; Graham, 2005). The concept of probability is applied in many fields like investments, insurance and most businesses. Students at the Colleges of Education need the concept of probability when designing objectives for lesson plans to teach mathematics at the basic level of Ghanaian education; and in their project work for statistical analysis and decision making. This

\footnotetext{
${ }^{1}$ Hamidu Ibrahim, Department of Mathematics, Bagabaga College of Education, Tamale-Ghana. Ibrahimbukari@gmail.com

${ }^{2}$ Asiedu-Addo, Department of Mathematics Education, Faculty of Education, University of Education, Winneba-Ghana.samasieduadd@yahoo.com

Open Access article distributed under the terms of the Creative Commons Attributions License [CC BY-NC-ND 4.0] http://creativecommons.org/licenses/by-nc-nd/4.0. DOI: https://dx.doi.org/10.4314/ajesms.v15i2.13
} 
Effect of problem-based learning on Colleges of Education students' achievement in probability and attitude towards solving probability related problems

\section{H. I. Bukari, \& S.K. Asiedu-Addo}

application of probability concepts has been a problem for most students at the Colleges of Education in Ghana.

In most cases, students have been found to approach probability as procedural and formulaoriented. This prevents them from experiencing the richness of probability and the many approaches that could be used to develop competencies in probability. Agyapong (2014) posits that most students at the Senior High Schools in Ghana have difficulty in understanding basic probability concepts. According to Mereku (2010), mathematics teachers in Ghana used traditional method of teaching and lesson delivery was teacher-centred because of that students lack mathematical analysis and logical reasoning and that mathematics pedagogy should be made practical for pre-service teachers (Asante \& Mereku, 2012). The Chief examiner report of University of Cape Coast (2018) on Colleges of Education course: Statistics and Probability outlined students' difficulties in understanding probability concepts, student's inability to use tree diagrams in answering probability problems and student's inability to solve and complete probability problems. Zahner and Cortex (2012) posits that, schematic diagrams such as Venn diagrams for compound events and outcome tree diagrams for sequential experiments have been an integral part of probability problem solving. Vygotsky (1978) pointed out that when students are challenged by working with diagrams, they become useful within their boundary of competence and the zone of proximal development.

Students' difficulties, poor academic achievement and poor attitudes toward probability problems can be largely attributed to instructional approach to teaching and learning that is not studentcentred approach. Traditional method of teaching and learning situations have been and still dominant instructional approach at the Basic level, Senior High School level and Colleges of Education in Ghana. There is therefore the need to shift in study habits from traditional approach to Problem-Based Learning pedagogical approach. This require an external behavioural change and internal psychological mindset change and this fundamental shift could be a long and difficult process if Problem-Based Learning (PBL) is not well implemented in the classroom context.

One major way to help PBL students make efficient and effective transition from traditional learning mindset to a PBL mindset is to explicitly teach them the philosophy of PBL. Knowing why and how concepts are being develop is the philosophy of PBL and the rationale for application of PBL as an instructional approach, may help students develop positive attitude to probability. This positive attitude would promote more active participation in the learning process and as a result would increase effective learning outcome and a change of mindset. Hence, tutors have to demonstrate appropriate scaffolding deem necessary for developing students' abilities and habits of the mind in assuming the role and tasks required in PBL environments or learning situations.

Another critical point is helping students to develop the mindset of taking responsibility for their own learning through collaborated activities. In PBL environments, the main aim is for the students to learn how to solve problems independently by conducting a scientific good research and reasoning process. One way of evaluating PBL students should be whether the students can articulate the critical elements of the problems, their process for solving it, and the solution proposed and defend their proposed solution and the rationale, rather than whether they match predetermined answers. When this is achieved then PBL become additional knowledge for mathematics educators in the implementation of PBL to teaching and learning process in probability problems. Thus, Problem-Based Learning is student-driven constructivist pedagogical approach to learning in which students through collaborated activities in smaller groups blend knowledge and skills to find solutions to complex problems (Bukari, 2019). Problem-based learning approach has been one of the most popular curriculum innovations in education. It is 
because, the approach helps students have clearer mind, been flexible with diversified ways of thinking and is considered as a paradigm of multidisciplinary studies (Johari, Nor Hasniza \& Mokhtar, 2013). Problem-based learning is the combination of specific concepts in classroom context for increasing students thinking skills and problem-solving ability. Ertmer and Simons (2006) identified three types of challenges teachers are likely to face in problem-based learning such as employing a culture of collaboration and interdependence; adjusting to changing roles; and scaffolding students learning and performance. This finding is important for this study in which we empirically document that Colleges of Education students should move away from procedural and formula-oriented approach to tutors designing problem-based learning units like problem-based learning lesson plan, material development such as quality problem formulation, student problem-based learning presentation skills and tutor facilitation skills.

In addition, the challenge of globalisation today requires students to master problem-solving skills and also have positive attitudes and values besides good conceptual knowledge of mathematics (Shahbodin \& Zareema, 2013).

\section{Theoretical framework}

This study reviewed Polya's (1945) problem-solving techniques and Atteh, Appoh-Andam and Obeng-Denteh (2017) problem-solving skills. Polya identified four basic steps of problem solving which had become the framework often recommended for teaching and assessing problem solving skills which include: understanding the problem, devising a plan to solve the problem, implementing the plan and reflecting on the problem (Looking back). Most mathematics classroom in Ghana, the teacher does most of the talking, questioning and thinking thereby making disposition of students in a passive role rather than an active role. This form of learning does not encourage critical thinking and problem solving on students. Teachers should therefore plan and create many opportunities for students to engage in problem solving where critical thinking becomes an integral part to provide the greatest benefit to students (Atteh, Appoh-Andam \& Obeng-Denteh, 2017). They suggested four 4-step guidelines that can be implemented in any mathematics classroom to help students acquire problem-solving skills, which include: holistic understanding of the problem, identify method(s) for solution, apply the method(s) for solution and check the accuracy of the problem. The theoretical framework was further based on (Othman, Berhannuddin \& Abdullah, 2013), Problem-Based Learning Cycle model in probability problemsolving where students use Problem-Based Learning approach which conveyed information that helped students solve problems using tree diagrams, Venn diagrams and tables rather than the use of lecture-discussion approach such as formulae and calculations. This Problem-Based Learning cycle made students to collaborate in groups to learn more about the problem by making findings, communicating to each other, apply knowledge and skills which made students enjoyed the fruits of active learning. This Problem-Based Learning cycle created room for students to explore in many real-life probability problems by going strictly to the stages and applying the cycle appropriately. 
Effect of problem-based learning on Colleges of Education students' achievement in probability and attitude towards solving probability related problems

H. I. Bukari, \& S.K. Asiedu-Addo

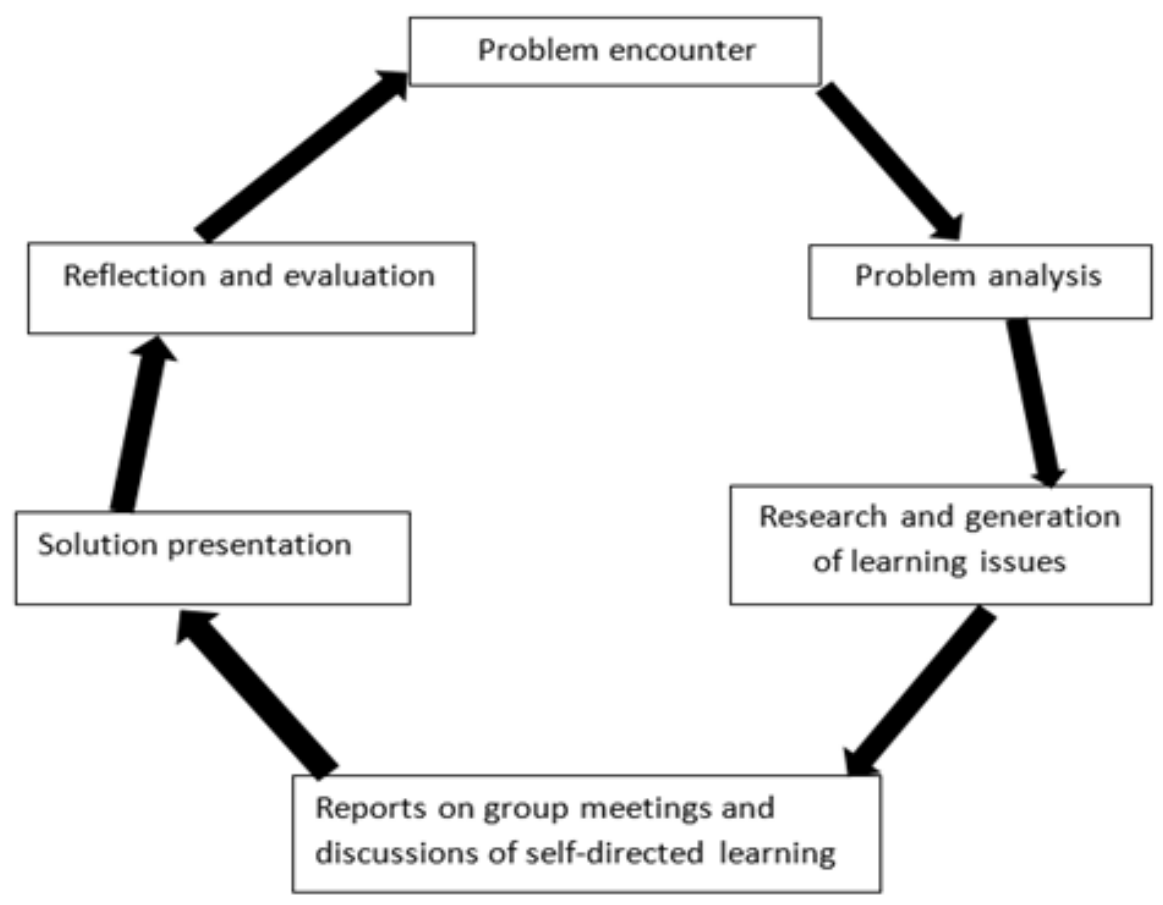

Figure 1: Problem-Based Learning cycle

Source: Othman e. al. (2013)

This Problem-Based Learning cycle was adapted because of students learning time and space which include: classroom context, outside classroom, individual learning, group learning, assisted learning and self-directed learning. The cycle made students brainstormed on probability problems; formulated learning issues and self-directed learning; reported on group meetings and discussed self-directed learning; reported on solution presentation and evaluation of self-directed learning. Finally, students reflected and evaluated learning issues and defined further action.

\section{Conceptual Framework of the Study}

The conceptual framework outlined the effect of the problem-based learning on the dependable variables and how the processes could lead to probability achievement of Colleges of Education students in Tamale Metropolitan of Ghana. 


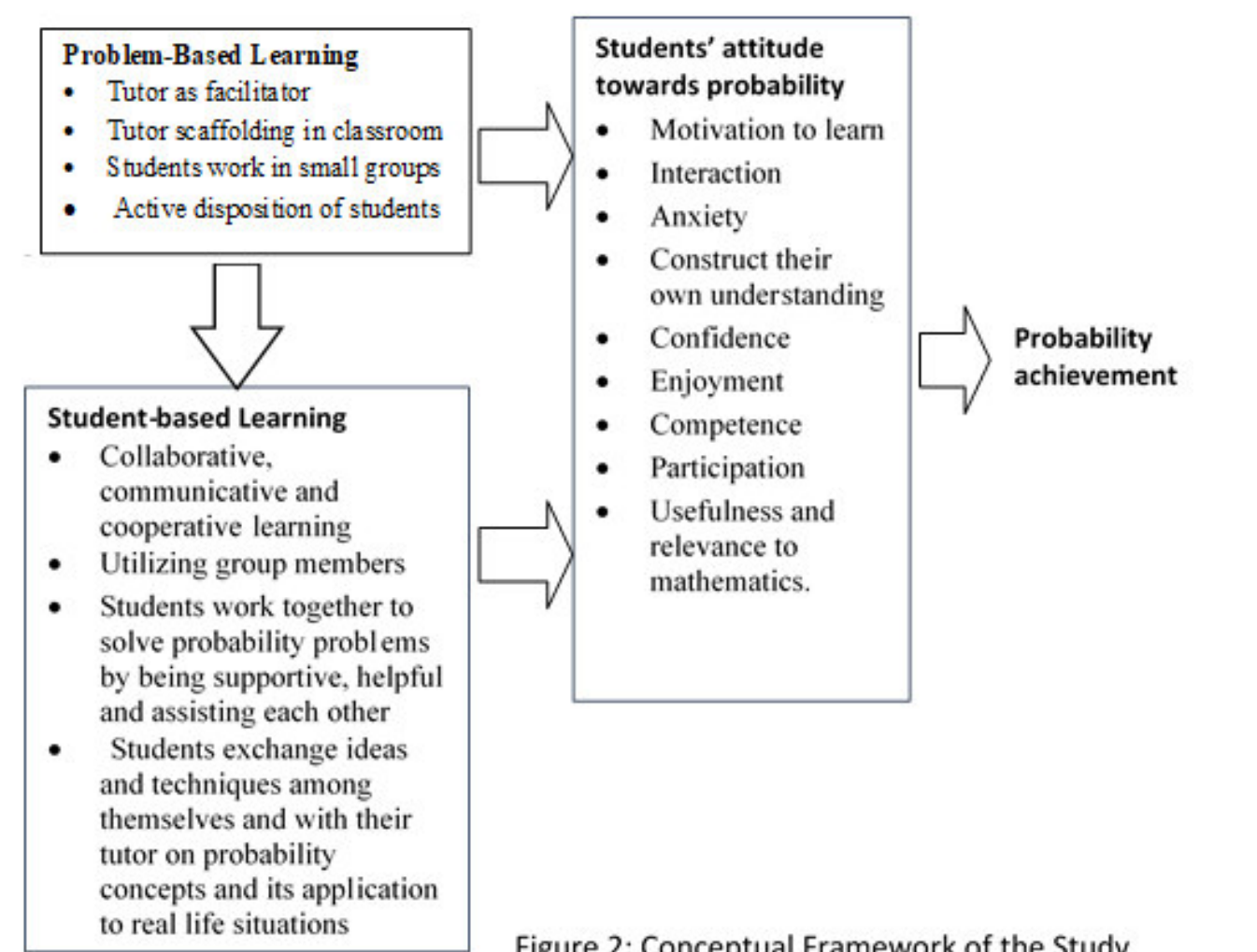

Figure 2: Conceptual Framework of the Study Source: Pale (2016)

\section{Purpose of the Study}

The purpose of this study was to investigate the effect of problem-based learning approach on Colleges of Education students' achievement in, and attitude toward, the learning of probability in Tamale Metropolitan of Ghana. The following questions were therefore framed to guide the study:

1. What difficulties do Colleges of Education students' have in solving probability problems?

2. What is the effect of Problem-Based Learning on Colleges of Education students' achievement in probability?

3. What are the attitudes of Colleges of Education students toward solving probability problems?

\section{Methods}

A quasi-experimental pre-test post-test two group design was used for this study. The study subjects comprised 51 students in the control group and 49 in the experimental group of Bagabaga College of Education and Tamale College of Education in the Tamale Metropolitan of Ghana. Convenience sampling technique was used in selecting the region and the two Colleges of Education in Tamale due to accessibility, geographical proximity, availability and willingness of students to participate and transportation convenience. Simple random sampling technique was also used in categorising the two Colleges of Education into control group and experimental group and selecting classes for the two groups.

Probability achievement pre-test was administered to both control and experimental groups. The Probability achievement pre-test scores were analysed using descriptive and independent samples t-test. An intervention was carried out for five weeks, where the experimental group was exposed 
Effect of problem-based learning on Colleges of Education students' achievement in probability and attitude towards solving probability related problems

\section{H. I. Bukari, \& S.K. Asiedu-Addo}

to Problem-Based Learning instruction and the control group exposed to Traditional Method instruction. Probability achievement post-test was administered to both groups after the intervention. The post-test scores were analysed using analysis of covariance (ANCOVA) based on the assumptions that, there was a significance difference in the pre-test scores of both groups. A paired samples t-test was further used on pre-test post-test of control and experimental groups.

A Likert-scale questionnaire was administered to students in order to find out about their views or perceptions on Problem-Based Learning and Traditional method and also their attitude toward probability problems. A five-point Likert scale of 30 items, which were scaled as 1-Strongly Disagree, 2-Disagree, 3-Undecided, 4-Agree and 5-Strongly agree. The data collected were analysed quantitatively based on the constructs: views about probability, personal confidence, application of Problem-Based Learning Cycle model, usefulness of probability and effectiveness of Problem-Based Learning approach using frequency count (Percentages) in the analysis of the results of this study.

A semi-structured interview was conducted on a sample of 10 students based on simple random sampling. The interview was sound recorded and transcribed. The data was analysed in themes such as trustworthiness, dependability, confirmability and transferability.

\section{Results/Findings}

With research question on what difficulties do Colleges of Education students' have in solving probability problems? A descriptive analysis of pre-test results of the control group and the experimental group on Table 1 answered the research question. The results on the Table 1 showed that both the control and experimental groups had difficulties in analysing probability concepts, inability to use tree diagrams and tables and application of probability to real life situations.

Table 1: $\quad$ Students' Scores on the Key Abilities and Skills Assessed in the Pre-test of Control and Experimental Groups

\begin{tabular}{llcc}
\hline & & $\begin{array}{c}\text { Control } \\
\text { Group }\end{array}$ & $\begin{array}{c}\text { Experimental } \\
\text { Group }\end{array}$ \\
& Students Ability & N (\%) & \\
\hline Function/ Skill & Able to analyse & $23(45 \%)$ & $19(39 \%)$ \\
& Unable to analyse & $28(55 \%)$ & $30(61 \%)$ \\
Use of tree diagram and & Able to solve & $15(29 \%)$ & $12(25 \%)$ \\
tables & Unable to solve & $36(71 \%)$ & $37(75 \%)$ \\
Application to real-life & Able to apply and determine solution & $11(22 \%)$ & $14(29 \%)$ \\
and Solution & Unable to apply and determine solution & $40(78 \%)$ & $35(71 \%)$ \\
\hline
\end{tabular}

\section{Independent samples $t$-test of pre-test results}

The independent samples t-test was used to analyse pre-test scores of both groups. Before the independent t-test the following assumptions were looked at: independence of observation, level of measurement and homogeneity of variance. In this study, it was assumed that the observation of the data was independent since two different Colleges of Education were used. In other words, it was considered that students' responses were not influenced from each other. Besides, the achievement and attitudes were the dependent variables and Problem-Based Learning the independent variable, hence it was assured that the level of measurement assumption was assured. The Table 2 was based on homogeneity of variance assumption. 
Table 2: $\quad$ Levene's Test Results for Probability Achievement Test (PAT) Scores

\begin{tabular}{lccc}
\hline F & df1 & df2 & P-value \\
\hline PAT (Pre-test) 0.03 & 1 & 98 & 0.84 \\
\hline
\end{tabular}

Lastly, homogeneity of variance assumption was assured since significance value in Levene's test was greater than $\alpha=0.05,[\mathrm{~F}(1,98)=0.03, \mathrm{P}=0.84]$. The variance within each group was equally distributed. The assumptions were met, t-test analysis was conducted to check if there was significance mean difference in pre-test scores of both control and experimental groups.

Table 3: Independent Samples T-test of Pre-test of Probability Achievement Test (PAT)

\begin{tabular}{llllllll}
\hline Group & $\mathrm{N}$ & Mean & SD & F & t-value & df & P-value \\
Experimental & 49 & 9.22 & 7.94 & & & & \\
& & & & 0.03 & 2.82 & 98 & 0.01 \\
Control & 51 & 13.69 & 7.91 & & & & \\
\hline
\end{tabular}

The results in Table 3, of pre-test scores of Probability achievement was statistically significant [ $\mathrm{t}(98)=2.82, \mathrm{P}=0.01]$. It was therefore concluded that, there was a statistically significant difference between the Control and the Experimental groups regarding student's pre-test scores of Probability Achievement Test before the treatment.

Research Question on what is the effect of Problem-Based Learning on Colleges of Education students' achievement in probability?

If there was no statistically significant difference between pre-test scores of both control and experimental groups, then independent t-test analysis should be done to determine the effect of Problem-Based Learning on Colleges of Education students' achievement in probability. Since there was significant difference in the pre-test mean scores of both control and experimental groups and on the assumptions to reduce errors of variance and also eliminate confounding variable, an analysis of covariance (ANCOVA) had been carried out to adjust post-test mean scores in order to determine the effect of problem-based learning on Colleges Students achievement in probability as shown in Table 4.

Table 4: $\quad$ ANCOVA results on probability achievement scores obtained by the experimental and control groups in the post-test

\begin{tabular}{lllllll}
\hline & $\begin{array}{l}\text { Type III } \\
\text { Sum of }\end{array}$ & & Mean & & Partial Eta \\
Source & Squares & Df & Square & F & Squared & P-value \\
\hline Intercept & 14925.28 & 1 & 14925.28 & 130.21 & 0.573 & 0.00 \\
Pre-test & 17.04 & 1 & 17.04 & 0.15 & 0.002 & 0.70 \\
Group & 2759.03 & 1 & 2759.03 & 24.07 & 0.199 & 0.00 \\
Error & 11118.25 & 97 & 114.62 & & & \\
\hline Total & 62920.00 & 100 & & & \\
\hline
\end{tabular}

To understand if there was a meaningful statistical difference in the two groups post-test scores, an ANCOVA analysis was conducted as shown in Table 4. The results indicated a statistically significant difference of the two groups while adjusting post-test scores $[\mathrm{F}(1,97)=24.07, \mathrm{P}=$ 0.00] with Partial Eta Squared $=0.199$ suggesting that Probability achievement test of the 
Effect of problem-based learning on Colleges of Education students' achievement in probability and attitude towards solving probability related problems

\section{H. I. Bukari, \& S.K. Asiedu-Addo}

experimental group exposed to Problem-Based Learning performed better in the post-test than the control group exposed to Traditional method. The experimental post-test scores were adjusted according to their pre-test scores. The post-test and adjusted mean post-test scores were calculated as 27.57 to 27.69 respectively. The control group mean post-test and adjusted mean post-test scores were also calculated as 16.88 to 16.77 respectively. Table 5 showed paired sample t-test of post-test and pre-test scores of the Experimental group.

Table 5: Paired Samples T-test of Post-test and Pre-test Scores of Experimental Group

\begin{tabular}{lccccccc}
\hline Group & Tests & $\mathrm{N}$ & Mean & $\mathrm{SD}$ & t-value & $\mathrm{df}$ & P-value \\
\hline Experimental & Post-test & 49 & 27.57 & 11.13 & & & \\
& & & & & 9.03 & 48 & 0.00 \\
Experimental & Pre-test & 49 & 9.22 & 7.94 & & & \\
\hline
\end{tabular}

Table 5 showed a paired sample t-test carried out which compared the mean difference of posttest and pre-test scores of the Experimental group as the data met all the assumptions of paired sample t-test. The results of the paired samples t-test conducted, verify mean difference between the post-test and pre-test scores indicated that there was a significant improvement in the achievement of post-test scores $(\mathrm{M}=27.57, \mathrm{SD}=11.13)$ over pre-test scores $(\mathrm{M}=9.22, \mathrm{SD}=$ 7.94) at $\alpha<0.05$ level of significance, with conditions [ $\mathrm{t}(48)=9.03, \mathrm{P}=0.00)$. It was therefore concluded that, there was a statistically significant difference between the post-test and pre-test scores of students when taken through the use of problem-based learning approach.

This study therefore concluded that there was a significant difference between the post-test and pre-test scores and that the use of problem-based learning approach had indeed a positive effect on students' achievement in probability problems at the College level of Ghana's education. Table 6 showed paired sample t-test of post-test and pre-test scores of the Control group.

Table 6: $\quad$ Paired Samples T-test of Post-test and Pre-test Scores of the Control Group

\begin{tabular}{llllllll}
\hline Group & Tests & N & Mean & SD & t-value & df & P-value \\
\hline Control Group & Post-test & 51 & 16.88 & 10.19 & & & \\
& & & & & 1.90 & 50 & 0.06 \\
Control Group & Pre-test & 51 & 13.69 & 7.91 & & & \\
\hline
\end{tabular}

The results on Table 6 showed that there was no statistically significant difference of the pre-test scores $(M=13.69, S . D=7.91)$ against post-test scores $(M=16.88, S . D=10.19)$ at $[\mathrm{t}(50)=1.90$, $\mathrm{P}=0.06]$, the traditional method seems not to be significant difference in teaching of probability as compared to Problem-Based Learning approach. This was because the mean difference of 3.19 showed that the control group exposed to the traditional method was not very good in the understanding of probability concepts and its application to real life situations.

\section{Probability Attitude Scale Analysis}

In this study, attitudes toward probability were measured by a 5-point Likert scale questionnaire. The questionnaire elicited responses on five attitude related constructs, namely interest in probability, personal confidence in probability, application of problem-based learning cycle, usefulness 
of probability and effectiveness of problem-based learning. Table 7 shows the mean number respondents agreeing or disagreeing with the five attitude constructs

Table 7 Mean number respondents agreeing or disagreeing with the five attitude constructs

\begin{tabular}{lccc}
\hline Constructs & Agree & Disagree & Undecided \\
\hline Interest in probability & 38.3 & 51.9 & 9.8 \\
Personal confidence & 64.2 & 29.1 & 6.7 \\
Application of problem-based learning cycle & 79.6 & 0 & 20.4 \\
Usefulness of probability & 47.0 & 33.2 & 19.8 \\
Effectiveness of problem-based learning & 74.2 & 16.7 & 9.2 \\
\hline
\end{tabular}

The results on Table 7 indicate with the construct of "personal confidence" the high percentage responds $(64 \%)$ indicated student's confidence in solving probability problems resulted in positive attitude toward probability problems. The construct "application of problem-based learning cycle" the result indicated $79.6 \%$ of students agree that, they used problem-based cycle model in solving probability problems and this had improved their understanding of probability concepts and applications to real life situations, whilst no student disagree to the statement and $20.4 \%$ were undecided on whether problem-based learning cycle model really helped them solve probability problems.

With the construct "usefulness of probability" the results indicated the importance of probability to students but only $47 \%$ of students agreed that probability concepts are useful. Finally, with the construct "effectiveness of problem-based learning" the high percentage (74\%) of respondents agreed on the effectiveness of problem-based learning in those statements. They think problembased learning helped them to think critically about different solutions before making decisions, whilst $16.7 \%$ disagree to the statement and $9.2 \%$ were undecided.

In conclusion, the results indicated that students hold positive views about probability and their confidence level has increased tremendously toward probability problems. This result showed that the intervention was successful and students saw probability concepts not difficult but rather interesting and joyful.

\section{Analysis of Interview Results}

The sound interviews recorded were transcribed verbatim. The few sketches of outcome tree diagrams made by the interviewees were added to these transcriptions. All transcriptions were read carefully at different times to become familiar with the data and to achieve emersion of data. When the researcher read the transcripts, initial reflective notes were made and coded in relevance to: trustworthiness, dependability, confirmability and transferability. During the semi-structured interviews students often struggled before coming out with the answer in an explicit way. This phenomenon was noticeable in the answers to items 5 and 10 in which the students were asked to evaluate the likelihood of a coin tossed twice with a die and also a die thrown twice. Not only did they doubt between different sequences because they conceptualized and understood techniques in a different way. They also doubted between different 'beliefs' on the matter as a whole, that was between the 'fact' that as such every sequence was equally likely on one hand (Analytical reasoning). Items 2 and 7 were linked to one another, however, the students gave divergent answers on the linked Probability items and followed divergent approaches to answer these linked items. 
Effect of problem-based learning on Colleges of Education students' achievement in probability and attitude towards solving probability related problems

\section{H. I. Bukari, \& S.K. Asiedu-Addo}

Moreover, item 9 was purely real-life probability problem, most students said they were not taught Probability at the Senior High School using outcome tree diagram hence could not apply (outcome tree orientation) in solving the problem, but they confirmed after the intervention such problems have now been easy for them to solve. Many of the students now see Probability problems as useful and would apply knowledge to teach students at basic level (Representative view).

Trustworthiness refers to the validity and reliability of the instruments. The test items were designed based on the mathematics course manual of Colleges of Education; hence validity was assured. The test items with the questionnaire and semi-interview guide were piloted to test reliability of the instruments. The pilot study resulted in changes in the instruments with regard to number of questions, duration and understanding of key words.

Dependability on the other hand, is the extent to which the study could be repeated by other researchers and the findings would be consistent. This was assured because a mathematics tutor from a different College of Education observed instructions on both the control and experimental group and admitted that lessons delivery was neutral without bias and also monitored the data collection process and analysis stage, hence the results of the findings can be dependable.

For example, a respondent reported that

"I used to dodge Statistics and Probability lessons at the Senior High School level because it was difficult to understand the concepts and I only guess the objectives part of the test and left the theory unanswered. But with the new approach using problem-based learning, to be honest with you (Researcher) if I were not be part, I would have done myself a great loss and that Probability is very simple especially using tree diagram to solve probability questions relating to real life situations".

The interview results confirmed the true reflection of the results of the pre-test and post-test scores. After the post-test the researchers made photocopies of the marking scheme and gave them to mathematics tutors to mark in order to avoid biasness and personal influence. In fact, the difference in the results of the marking was just minus one and plus one with other scripts being the same marks. This confirmed what a respondent said with regard to the theme of confirmability.

Specifically, on the issue of how students answer the pre-test question, respondent $\mathrm{E}$ and $\mathrm{B}$ responded that;

Sir, back at Senior High School, I didn't know there was a tree diagrams to solve probability questions. So, using the probability tree diagram I was struggling along the lines, I got somewhere and got confused, as how to proceed because I didn't have any idea about the tree diagram (Responder E).

I couldn't do it because I remembered I was taught probability back at Senior High School but I couldn't get the concept well, because probability questions are 'trickiest' so if the teacher who is to teach is not well verse with it or does not understand the concepts, then students will find it very difficult to solve questions on probability. I had no idea about tree diagram in solving probability questions, but thank God, after the intervention I now find probability questions interesting and understandable due to the application of problem-based learning and use of Polya's heuristics and PBL cycle model in solving problems and the use of tree diagram is now a thing of the past (Respondent B).

\section{Discussion}

In this study, the researcher sought to find out Colleges of Education students' achievement in probability problems and their attitude toward probability. The researcher in line with the standards, constructed test items on probability that all second-year students of Colleges of 
Education are expected to know. Ten (10) items were set to gather information on student's achievement in probability. The analysis was categorised according to students being able/unable to solve probability concepts, students being able/unable to use tree diagrams/tables to solve probability problems and finally, students being able/unable to determine real life situation of probability problems of both the control group exposed to Traditional method and the experimental group exposed to Problem-Based Learning approach. The focus was on students attaining a score not less than $50 \%$ for being able to apply the various skills or better still $70 \%$ of the test.

The analysis showed that, students obtained marks less than the 50\% indicating their ability to apply various skills assessed and above $50 \%$ as their inability to apply the same skills assessed. From the quantitative analysis of students' general performance on the items, one can conclude that majority of the students at the Colleges of Education lack basic concepts in Probability needed for everyday life as most of the students performed poorly on the items with regard to the use of tree diagrams and tables.

On the findings of students' probability achievement on probability concepts, students recorded low performances where they achieved below 50\%. This raises a lot of concerns especially when Ghanaian mathematics classroom discourse is dominated by content of procedures and formulaoriented.

From the analysis of students' performance on the ability to use tree diagrams and tables to solve probability problems. Students inability to use outcome tree diagrams and tables including Venn diagrams, recorded above $60 \%$ as their inability to apply tree diagrams in solving problems. Students scored above $70 \%$ mark as their inability to determine probability problems related to real life situation. This represented their weakest performance in applying. These findings showed that Colleges of Education students have difficulties in solving probability problems.

The analysis using paired samples t-test on post-test scores and pre-test scores of experimental group showed that students performed better in the post-test than pre-test in the experimental group and this finding is consistent with the finding of Uygun and Tertemiz (2014) where there was a statistical difference between experimental group pre-test and post-test achievement mean scores.

The results of this study had shown that students taught probability using problem-based learning (PBL) performed better than their colleagues taught using traditional method. From the analysis of post-test scores of both control and experimental groups using ANCOVA, the findings revealed the efficacy of the use of PBL in enhancing student's achievement in probability and this finding is in consonance with (Uygun \& Tertemiz, 2014; Espinoza \& Sanchez, 2014; Olpak, Baltaci \& Arican, 2018) who attested that PBL students performed better than the traditional method. Partial Eta squared of 0.199 indicated a large effect size of Problem-Based Learning as an effective instructional approach in teaching the concepts of Probability, the use of tree diagrams in applying to real life probability problems. The larger Partial Eta-squared showed the positive impact of PBL in probability instructions and its importance in the achievement scores of students at the Colleges of Education in Tamale Metropolitan of Ghana. The positive effects of PBL such as becoming a good problem solver, demonstrating effective critical thinking ability was in consistence with the finding of Ajmal, Jumani and Malik (2016), the importance of being independent to do selfdirected learning and being able to work collaboratively were also shown in this study.

However, the findings revealed that the traditional method of instruction was not good enough for teaching and learning of probability concepts and its application to real life situation when a paired samples t-test was used in analysing post-test scores and pre-test scores of the control group exposed to traditional method. The findings in this study on the attitudes of students toward 
Effect of problem-based learning on Colleges of Education students' achievement in probability and attitude towards solving probability related problems

H. I. Bukari, \& S.K. Asiedu-Addo

probability was contended that the PBL group used Polya's and PBL Cycle model problem solving technique more effectively in solving probability problems. The results revealed that PBL helped students overcome their difficulties of communication with their colleagues during group discussions of probability problems.

The interview findings revealed that most teachers at Senior High Schools in Ghana do not use outcome tree diagrams to solve sequential experiments of probability problems.

PBL had also displayed good probability communication skills and on whether PBL motivates one to learn probability problems, most of the students agree that problem-based learning motivates students to learn probability which is consistent with the finding of (Han et al., 2016) that most students agreed they would be more motivated to learn mathematical concepts that are meaningful. The finding of the study also revealed that PBL approach is very effective for teaching Probability since it created a number of creative thinkers, self-directed learners, critical decision makers, problem solvers which is needed most for the $21^{\text {st }}$ century world.

\section{Conclusion}

It can be argued from the results that students' weak performance and difficulties in solving probability problems were largely due to their inability to understand the problem, devising a correct plan, carrying out their plans and inability to state the correct answer. The intervention enabled students to do team work, collaborate, cooperate and communicate effectively together; and also made them discover new strategies and apply to probability concepts and problems.

Problem-based learning approach developed in students; critical thinking, good problem solvers and self-directed learners. This would lead to life-long memory of probability concepts. It also motivated students and made them to develop interest in learning probability problems related to real life situations.

Problem-Based Learning approach made students to become good problem solvers, critical thinkers, self-directed learners and critical decision makers which is very much needed for this competitive world and in the field of mathematics education.

\section{References}

Agyapong, D. (2014). Using Guided Discovery Method to Improve Students' Ability to Solve Problems of Basic Concepts of Probability at Assin Nsuta Senior High School. WinnebaGhana: Unpublished M.Ed Dissertation, University of Education.

Ajmal, F., Jumani, N.B. \& Malik, S. (2016). Utilizing Problem-Based Learning in Pre-Service Teacher Education: Experiences of Prospective Teachers in Pakistan. Journal of Education and Human Development,5(2), 215-222. URL:https://doi.org/10.15640/jehd.v5n2a25.

Arthur, Y., Asiedu-Addo, S., \& Assuah, C. (2017). Students' Perception and Its Impact on Ghanaian Students' Interest in Mathematics: Multivariate Statistical Analytical Approach. Asian Research Journal of Mathematics, 2456-477X, 4(2), 1-12. doi:10.9734/ARJOM/2017/33023.

Asante, J. N., \& Mereku, D. K. (2012). The effect of Ghanaian Pre-service teachers' content knowledge on their mathematical knowledge for teaching basic school mathematics. African Journal of Educational Studies in Mathematics and Sciences 10, 23. 
Atteh, E., Andam, E., \& Obeng-Denteh, W. (2017). Problem solving framework for Mathematics Discipline. Asian Research Journal of Mathematics, 4(4), 1-11. doi:10.9734/ARJOM/2017/32586.

Borovnik, M. (2012). Multiple perspectives on the concept of conditional probability. Unversity of Klagenfurt. Avances de Investigacion en Education Matematica, 2, 5-27.

Bukari, H. I. (2019). Using Problem-Based Learning to Enhance Junior High School Students' Understanding and Attitudes towards Linear Equations Word Problems. The International Institute for Science, Technology and Education (IISTE). Journal of Education and Practice, 10(3), 126-135. doi:10.7176/JEP/10-3-14

Chief Examiner's Report, University of Cape Coast (2018). Statistics and Probability : Diploma in Basic Education. Ghana: University of Cape Coast.

Ertmer, P.A., \& Simons, K.D. (2006). Jumping the PBL implementation hurdle: Supporting the efforts of K-12 teachers. Interdisciplinary Journal of Problem-Based Learning, 1(1), 4054. http://dx.doi.org/10.7771/1541-5015.1005

Espinoza, M. C., \& Sanchez, I. S. (2014). Problem-Based Learning to teach and learn Statistics and Probability. Paradigma, 35(1), 103-128

Graham, A. J. (2005). Exploring Probability in School: Challenges for teaching and learning. New York: Springer.

Han, S. H., Shahrill, M., Tan, A., Tengah, K. A., Jaidin, J. H., \& Jawawi, R. (2016). Administering Problem-Based Learning (PBL) Approach in the Teaching of College-Level Mathematics. International Conference on New Horizons in education (INTE), 1-13. doi:DOI: 10.13140/RG.2.1.33647608

Johari, S., Nor Hasniza, I., \& Mohktar, M. (2013). Implementation of PBL in Higher Education Institution and Its Impact on Students' Learning: $4^{\text {th }}$ International Research Symposium on PBL (IRSPBL)- Aalborg University Denmark.

Lee, H., Doerr, H., Tran, D., \& Lovert, J. (2016). The Role of Probability in Developing Learners' Models of Simulation Approaches to Inferences. Statistics Education Research Journal, 15(2), 216-238.

Mereku, D. (2010). Five Decades of School Mathematics in Ghana. Mathematics Connection, 9(8), 73-88

Olpak, Y. Z., Baltaci, S., \& Arican, M. (2018). Investigating the effects of peer instruction on preservice Mathematics teachers' achievements in Statistics and Probability. Journal of Education Information Technology, 1-18. doi:10.1007/s10639-018-9717-3

Othman, H., Berhannuddin, M. S., \& Abdullah, S. (2013, July). 5 Ladders of Active Learning: An Innovative Steps in Problem-Based Learning Process. In: 4th International Research Symposium on Problem-Based Learning.

Pale, J. W. (2016). Teacher and Student Based Instructions on Probability Achievement Outcomes and Attitudes of Secondary School Students in Bungoma North, Kenya. Journal of Education and Practice., 7, 43-53.

Polya, G. (1945). How to solve it. Princeton, New Jersey: Princeton University Press.

Pratt, D. (2005). How do teachers foster students' understanding of Probability? In Graham, A. Jones. Exploring Probability in School. Springer Link Publication. 
Effect of problem-based learning on Colleges of Education students' achievement in probability and attitude towards solving probability related problems

H. I. Bukari, \& S.K. Asiedu-Addo

Shahbodin, F., \& Zareema, R. (2013). The use of PBL Math Game as a Problem-Based Learning Tool. 4th International Research Symposium on PBL (IRSPBL). Denmark: Aalborg University.

Uygun, N., \& Tertemiz, N. (2014). Effects of Problem-based learning on students' attitudes, achievement and retention of learning Math Course. Education and Science, 39(174), 7590. doi:DOI: 10.15390/EB.2014.1975

Vygotsky, L. (1978). Interaction between Learning and Development. From: Mind and Society. Cambridge, MA: Harvard University Press.

Zahner, D., \& Cortex, J. E. (2012). The Process of Probability Problem Solving: Use of External Visual Representation. Mathematical Thinking and Learning, 12(2), 177-204. doi:http://dx.doi.org/10.1080/10986061003654240 